\title{
Arquitetura sísmica do sistema fluvio-estuarino da Baía de Sepetiba preservado na estratigrafia rasa da plataforma adjacente, Rio de Janeiro, Brasil
}

\author{
The seismic architecture of the Sepetiba fluvio-estuarine \\ system preserved on the shallow stratigraphic record on \\ the offshore inner-mid shelf, Rio de Janeiro, Brazil
}

\author{
Yasmin Lima Friederichs ${ }^{1 *}$, Antonio Tadeu dos Reis ${ }^{2}$, Cleverson Guizan Silva ${ }^{3}$, \\ Baptiste Toulemonde ${ }^{4}$, Renata Moreira da Costa Maia ${ }^{3}$, Josefa Varela Guerra ${ }^{2}$
}

RESUMO: A análise de dados de reflexão sísmica monocanal Boomer adquiridos na plataforma continental interna-média (até $-60 \mathrm{~m}$ de profundidade) ao largo da Baía de Sepetiba, Rio de Janeiro, Brasil, revelou a ocorrência de uma sucessão sedimentar preservada de $15-25 \mathrm{~m}$ de espessura, sismicamente interpretada como representando ambientes fluvio-estuarinos passando para marinhos rasos. A preservaçáo de unidades de corte e preenchimento de canais estuarinos, de provável idade Pleistoceno Tardio-Holoceno na plataforma interna-média (até $-30 \mathrm{~km}$ da costa), evidencia, pela primeira vez na área, a existência de um paleo sistema fluvial bastante desenvolvido preservado na plataforma rasa e correlato à bacia hidrográfica a montante que atualmente alimenta a Baía de Sepetiba. Além disso, uma série de elementos arquiteturais da sucessão sedimentar estuarina, como canais de maré retrogradantes, registra a evoluçáo do paleo sistema estuarino de um sistema aberto a um sistema parcialmente protegido durante a última deglaciação. A formação e erosáo de uma sucessão de ilhas-barreira isoladas e canais de maré durante a transgressão marinha que acompanhou a última deglaciação global persistiu até o desenvolvimento de uma superfície estratigráfica superior na área, interpretada como a superfície de máxima inundaçáo (MFS) no registro estratigráfico. A ilha barreira atual (Restinga da Marambaia) prograda sobre a MFS como uma feição deposicional regressiva, apontando para uma idade mais jovem do que $-5,8$ ka A.P., idade da transgressão máxima na área, de acordo com a literatura disponível.

PALAVRAS-CHAVE: Transgressão Pleistoceno Tardio-Holoceno; ambientes costeiros; plataforma interna-média; arquitetura de sistemas estuarinos; sísmica de alta resoluçáo.
ABSTRACT: The analysis of high resolution Boomer monochannel seismic reflection data acquired on the inner-mid shelf (up to - $60 \mathrm{~m}$ depth) offshore the Sepetiba bay estuarine system, Rio de Janeiro State, Brazil, revealed the occurrence of a $15-25$ m preserved sedimentary succession, seismically interpreted as fluvio-estuarine to shallow marine environments. Preservation of such presumable Uppermost Pleistocene-Holocene cut-and-fill estuarine units on the inner-mid shelf (up to $-30 \mathrm{~km}$ away from the coast) evidence for the first time in the area the existence of a rather developed paleoriver system and dominant denudation processes in the upstream catchment basin of Sepetiba region. As well as that, a series of seismic architectural elements within this estuarine succession, such as retrogressive tidal channels, records the evolution of the paleoestuarine system from an open to a partially-protected environment during the last deglaciation. The formation and erosion of a succession of isolated barrier islands and tidal channels during the transgression persisted until the development of an upper stratigraphic surface in the sedimentary record, interpreted as the Maximum Flooding Surface (MFS). The present day barrier island (Restinga da Marambaia) progrades over this MFS as a regressive depositional feature, pointing to an age of formation younger than $-5.8 \mathrm{ka}$, age of the maximum transgression in the area, according to the literature.

KEYWORDS: Latest Pleistocene-Holocene transgression; coastal environments; inner-mid shelf; estuarine depositional architecture; high resolution seismics.

\footnotetext{
${ }^{1}$ Programa de Pós-graduação em Oceanografia, Universidade do Estado do Rio de Janeiro - UERJ, Rio de Janeiro (RJ), Brasil. E-mail: yasmichs82@gmail.com 2Faculdade de Oceanografia, Universidade do Estado do Rio de Janeiro - UERJ, Rio de Janeiro (RJ), Brasil. E-mails: antonio.tadeu@pq.cnpq.br, josie.guerra@gmail.com 32Laboratório de Geologia Marinha - Lagemar, Universidade Federal Fluminense - UFF, Niterói (RJ), Rio de Janeiro, Brasil. E-mails: cguizan@id.uff.br, renata.ocn@gmail.com ${ }^{4}$ Programa de Mestrado em “Ingenierie et Geosciences du Littoral”, Université de Caen Basse-Normandie, Caen, France. E-mail: baptistetoul@gmail.com *Autor correspondente

Manuscrito ID 28077. Recebido em: 13/07/2012. Aprovado em: 20/01/2013
} 


\section{INTRODUÇÃO}

Este trabalho envolve a investigação dos sistemas sedimentares da plataforma interna-média até $\sim 60 \mathrm{~m}$ de profundidade ao largo da Baía de Sepetiba, Estado do Rio de Janeiro, porção nordeste da bacia de Santos, Brasil. O estudo focaliza a organização do registro estratigráfico sob a influência dos sucessivos deslocamentos das fácies sedimentares sobre a plataforma continental, induzidos principalmente pelas oscilações glacioeustáticas durante o Pleistoceno Superior-Holoceno ( $-130 \mathrm{ka})$. O estudo permitiu a proposiçáo de um cenário paleogeográfico da evolução do sistema estuarino da Baía de Sepetiba, integrando detalhes do registro estratigráfico da plataforma rasa adjacente à Restinga da Marambaia à evolução da configuração do sistema fluvio-estuarino atual (Fig. 1).
O trabalho é parte integrante de um projeto mais amplo de investigação dos ambientes deposicionais hoje presentes na plataforma rasa ao largo do Estado do Rio de Janeiro, entre a Baía de Ilha Grande e a Foz do Rio Itabapoana, e sua acoplagem estratigráfica aos atuais ambientes costeiros e de plataforma externa, desenvolvido no âmbito de um projeto CAPES - Ciências do Mar intitulado "Estudos oceanográficos e geológico-geofísicos integrados nos ambientes de baías e de plataforma continental ao largo do Estado do Rio de Janeiro".

\section{MATERIAIS E MÉTODOS}

O trabalho conta com cerca de $700 \mathrm{~km}$ de linhas sísmicas de alta resolução (Fig. 1), coletadas com um sistema sísmico Boomer AA301 da marca Applied Acoustics

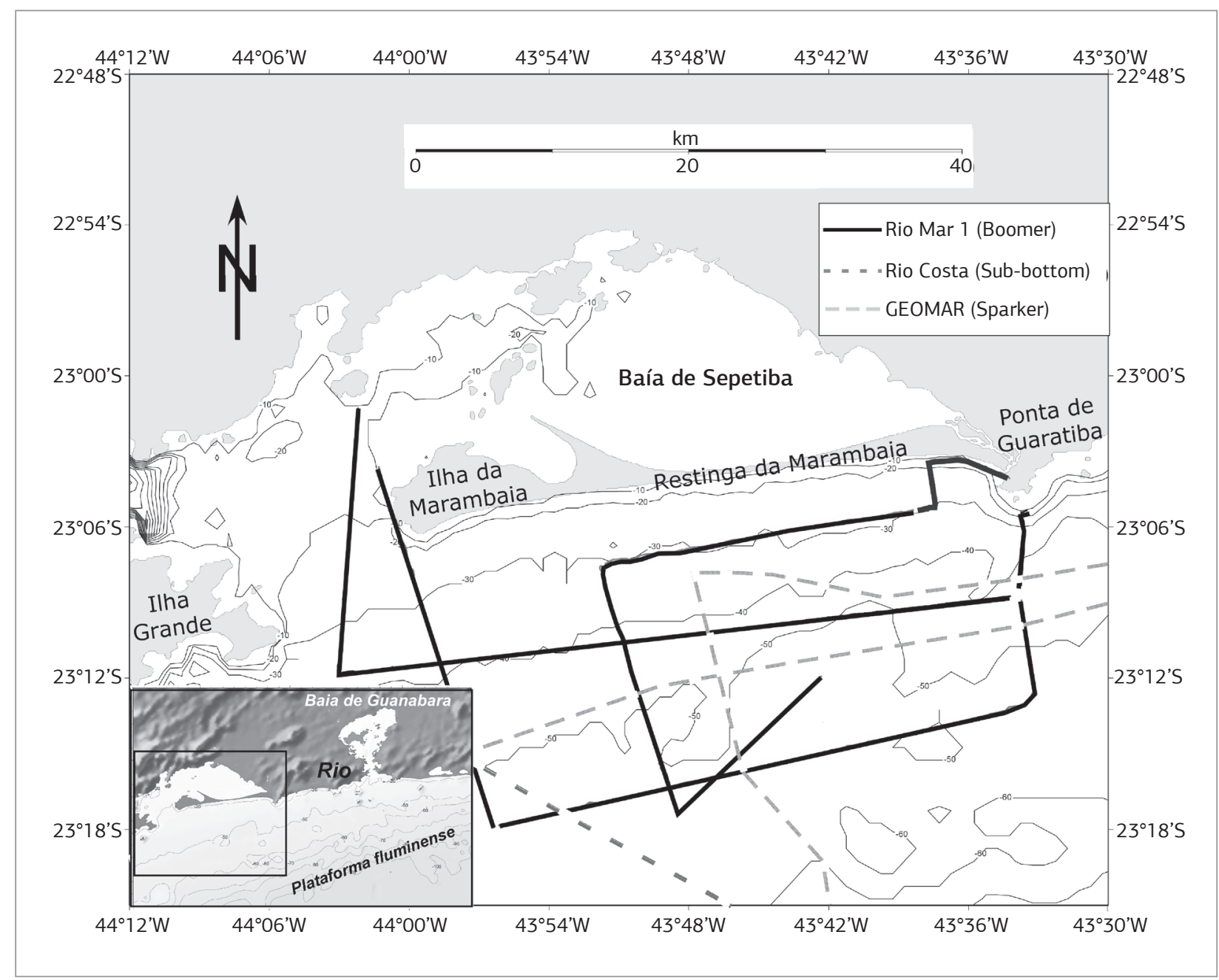

Figura 1. Mapa morfológico da área de estudo indicando o posicionamento das bases de dados Rio Mar 1 (presente estudo), GEOMAR (Maia et al. 2010) e Rio Costa (Reis et al., no prelo) utilizadas na correlação cronoestratigráfica das unidades sísmicas identificadas no presente estudo. Base de dados batimétricos extraída de General Bathymetric Chart of the Oceans (GEBCO). 
Engeneering Ltda. durante a Missão Oceanográfica Rio Mar I (agosto de 2010). A perfilagem sísmica foi realizada com a fonte operando com a potência de 200 - 300 Joules, com banda principal de frequência concentrada no espectro entre -500 e $4.500 \mathrm{~Hz}$, permitindo uma penetração do sinal acústico de $-70 \mathrm{~ms}$ abaixo do fundo submarino (cada $10 \mathrm{~ms}$ corresponde a $\sim 8 \mathrm{~m}$ de espessura sedimentar, para uma velocidade sísmica intervalar estimada em 1.600 $\mathrm{m} / \mathrm{s}$ ) e resolução vertical de $-0,5-2,0 \mathrm{~m}$. Os dados foram processados no sistema de aquisição CODA 500, por meio da aplicação de uma série de filtros para melhoria da razão sinal/ruído e de filtros do tipo swell filter para retirada dos ruídos de ondas do mar.

A interpretação dos perfis sísmicos foi feita de acordo com os princípios gerais da Sismoestratigrafia e da Estratigrafia de Sequências de Alta Resolução (sintetizados respectivamente em Mitchum \& Vail 1977 e Catuneanu 2006), que permitiram a identificação de fácies sísmicas indicativas de diferentes ambientes sedimentares (Fig. 2), de unidades deposicionais e de suas superfícies limitantes. A identificação de fácies sísmicas foi feita mediante a análise de parâmetros como: configuração, amplitude e frequência, e continuidade lateral e arranjo das reflexóes sísmicas, baseados em estudos de caso (por exemplo, Chaumillon et al. 2010).

\section{RESULTADOS}

A análise sísmica permitiu a identificação de oito unidades sísmicas na área de estudos: uma unidade basal $\mathrm{U}_{0}$, e sete unidades sobrepostas, limitadas acima e abaixo por superfícies lateralmente contínuas na área de estudo

\begin{tabular}{|c|c|c|c|}
\hline Fácies & Ilustração da assinatura sísmica & Configuração das reflexões & Interpretação \\
\hline$f_{0}$ & 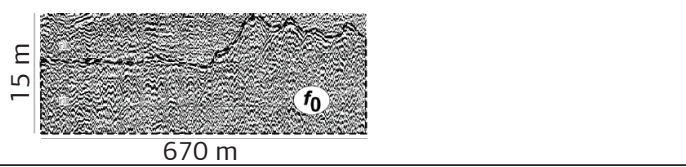 & $\begin{array}{c}\text { Corpos contínuos ou isolados } \\
\text { de formato pontiagudo cônico } \\
\text { ou de topo tabular, associados à } \\
\text { hipérboles de refração }\end{array}$ & Embasamento cristalino \\
\hline$f_{1}$ & 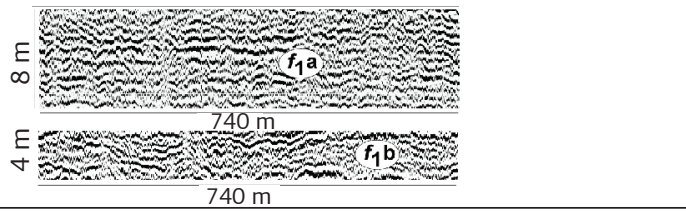 & $\begin{array}{c}\text { Refletores subparalelos } \\
\text { descontínuos e/ou caóticos com } \\
\text { presença de pequenos canais } \\
\text { isolados }\end{array}$ & $\begin{array}{c}\text { Fácies estuarinas } \\
\text { (fácies argilo-arenosas) }\end{array}$ \\
\hline$f_{2}$ & 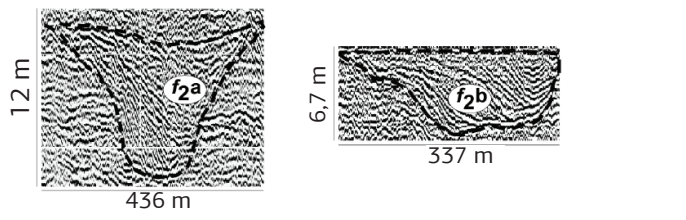 & $\begin{array}{l}\text { Refletores inclinados } \\
\text { preenchendo canais de } \\
\text { diferentes relevos relativos }\end{array}$ & $\begin{array}{c}f_{2} \mathrm{a}=\text { Preenchimento arenoso de } \\
\text { canais fluviais } \\
(\sim 10-15 \mathrm{~m} \text { de profundidade }) \\
f_{2} \mathrm{~b}=\text { Preenchimento arenoso de } \\
\text { canais de maré } \\
(\sim 5 \mathrm{~m} \text { de profundidade })\end{array}$ \\
\hline$f_{3}$ & 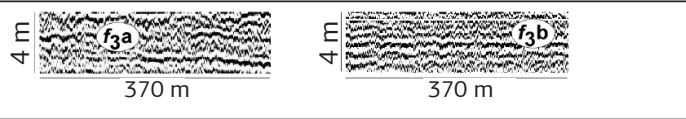 & $\begin{array}{l}\text { Refletores plano-paralelos } \\
\text { contínuos e amplamente } \\
\text { distribuídos }\end{array}$ & $\begin{array}{c}\text { Deposição marinha } \\
\text { de plataforma rasa } \\
\text { (fácies argilo-arenosas) }\end{array}$ \\
\hline$f_{4}$ & 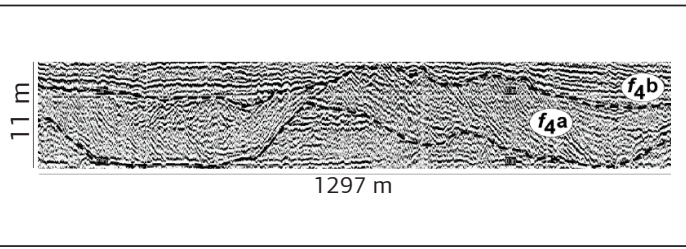 & $\begin{array}{c}f_{4} \text { a: Reflexões inclinadas } \\
\text { preenchendo canais, com } \\
\text { múltiplas feições de corte e } \\
\text { preenchimento } \\
f_{4} \text { b: Refletores plano-paralelos } \\
\text { e contínuos, preenchendo } \\
\text { depressões }\end{array}$ & $\begin{array}{c}f_{4} \mathrm{a}=\text { Migração lateral de canais } \\
\text { fluvio-estuarinos } \\
\text { (fácies arenosas) } \\
f_{4} \mathrm{~b}=\text { Fácies argilo-arenosas, } \\
\text { indicando preenchimento de } \\
\text { boca de estuário }\end{array}$ \\
\hline$f_{5}$ & 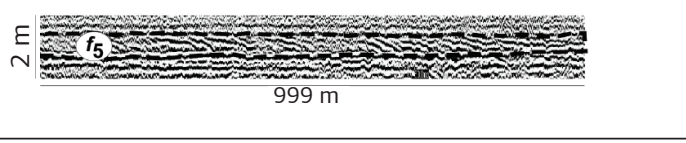 & $\begin{array}{l}\text { Corpos tabulares de pequena } \\
\text { espessura }(2-3 \mathrm{~m}) \text { com } \\
\text { refletores internos oblíquos de } \\
\text { alto ângulo }\end{array}$ & $\begin{array}{l}\text { Barras arenosas estuarinas } \\
\text { (fácies arenosas) }\end{array}$ \\
\hline$f_{6}$ & 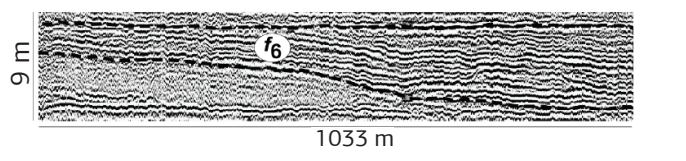 & $\begin{array}{l}\text { Refletores contínuos e } \\
\text { divergentes, com raras } \\
\text { canalizações }\end{array}$ & $\begin{array}{l}\text { Deposição argilo-arenosa } \\
\text { em embientes estuarinos } \\
\quad \text { protegidos } \\
\text { (fechados ou semifechados) }\end{array}$ \\
\hline
\end{tabular}

Figura 2. Definição e exemplos das principais fácies sísmicas observadas na área de estudo. A interpretação das fácies sísmicas $\mathrm{f}_{1}$ a $\mathrm{f}_{6}$ são derivadas de estudos de caso de ambientes sedimentares fluvio-estuarinos e marinhos rasos apresentados por Chaumillon et al. (2010) em uma série de publicações temáticas do volume especial French incised valleys and estuaries. 
(unidades $\mathrm{U}_{1}, \mathrm{U}_{2}, \mathrm{U}_{3}, \mathrm{U}_{4}, \mathrm{U}_{5}, \mathrm{U}_{6}$ e $\mathrm{U}_{7}$; Fig. 3). As unidades $\mathrm{U}_{1}-\mathrm{U}_{7}$ apresentam variação de espessura no sentido continente-plataforma, assim como grande variabilidade de fácies sísmicas laterais entre a porção proximal e distal da área de estudo (Figs. 3 e 4).

\section{Unidade sísmica $U_{0}$}

A unidade basal $\mathrm{U}_{0}$ é caracterizada por uma fácies sísmica transparente e/ou caótica, formando corpos pontiagudos cônicos em frequente associação com hipérboles de refração, ou ainda corpos tabulares de topo achatado

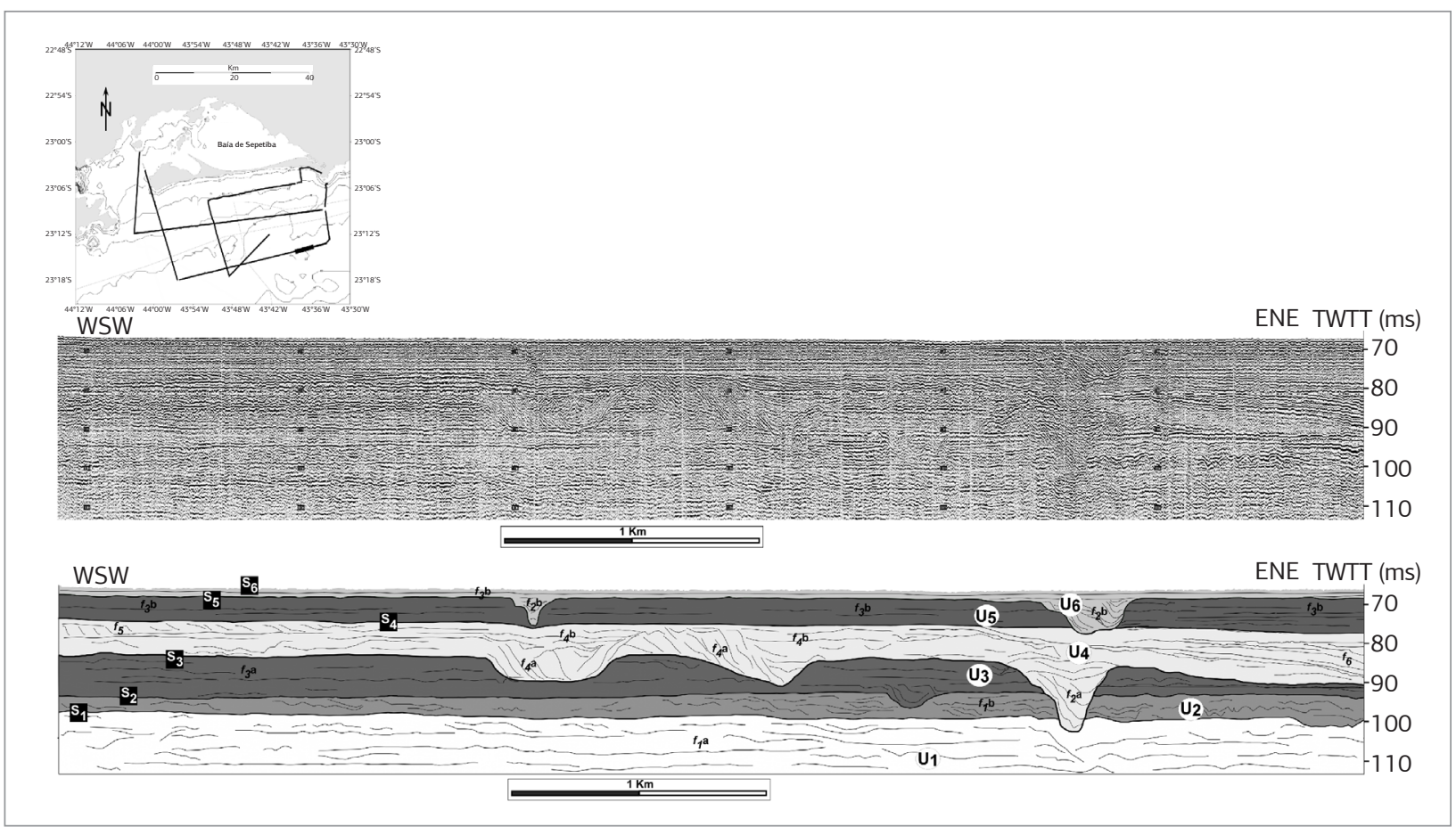

Figura 3. Perfil sísmico de orientação paralela à costa, localizado na porção sudeste distal da área de estudo (acima) e esquema interpretativo ilustrando as unidades sísmicas identificadas na área (abaixo). U: unidade; f: fácies.

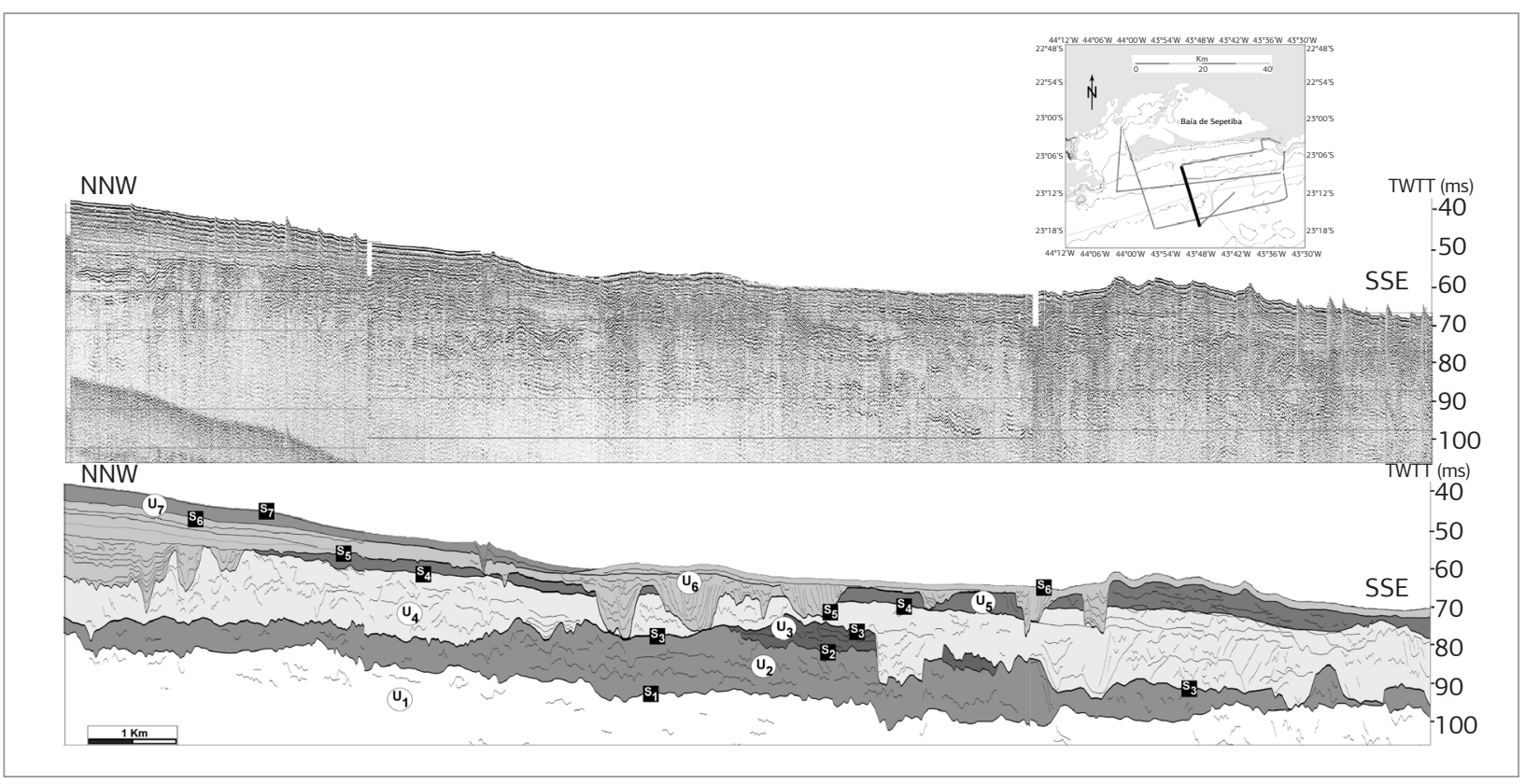

Figura 4. Perfil sísmico com orientação transversal à costa, localizado na porção central da área de estudo (acima) e esquema interpretativo ilustrando as unidades sísmicas identificadas na área (abaixo). U: unidade; f: fácies. 
(fácies fo, Fig. 2). Esses corpos interrompem localmente as unidades sísmicas sobrepostas e são interpretados como representando embasamento cristalino (Fig. 5), formando paleomorfologias semelhantes às atuais morfologias cristalinas emersas, como a chamada "ilha" da Marambaia e a Ponta de Guaratiba (Fig. 1). Tais corpos cristalinos, mesmo quando presentes à frente e próximos da atual Restinga da Marambaia, podem apresenta-se soterrados por algumas dezenas de metros de sedimento.

\section{Unidade sísmica $\mathrm{U}_{1}$}

A unidade sísmica $U_{1}$ representa a unidade sedimentar basal mapeada na área, e a mais pobremente imageada na área de estudo, por se encontrar no limite de penetração do sinal sísmico, não sendo assim possível a delimitação de sua base (Figs. 3 e 4). Essa unidade é expressa em toda área de estudos como uma unidade lateralmente contínua, limitada em seu topo por uma superfície erosiva e irregular, apresentando incisóes canalizadas (superfície $S_{1}$ ). Internamente, essa unidade é caracterizada por refletores subparalelos descontínuos a localmente caóticos, de baixa frequência relativa, e pela presença de feiçôes canalizadas de pequena dimensão $(-40-150 \mathrm{~m}$ de largura e $\sim 1,5 \mathrm{~m}$ de profundidade) ilustrados pela fácies sísmica $f_{1}$ a, interpretada como representado fácies estuarinas distais (Figs. 2 e 3).

\section{Unidade sísmica $\mathrm{U}_{2}$}

A unidade sísmica $\mathrm{U}_{2}$ apresenta seu topo limitado pela superfície $S_{2}$, caracterizada por morfologia irregular e por incisōes locais de canais (Figs. 3 e 4). Sismicamente, a unidade foi interpretada de forma semelhante à unidade $\mathrm{U}_{1}$, como representado fácies estuarinas distais, porém com refletores internos menos contínuos e mais caóticos (fácies $f_{1}$ b, Figs. 2 e 3), enquanto sua base pode ser caracterizada por fácies de preenchimento de canal fluvial localizados $\left(f_{2}\right.$ a, Figs. 2 e 4$)$. Essa unidade encontra-se preservada em toda área de estudo, no entanto apresenta grande variação de espessura no sentido continente-plataforma, se adelgaçando em direçáo ao continente, onde atinge $-5 \mathrm{~m}$ de espessura (Fig. 4).

\section{Unidade sísmica $\mathrm{U}_{3}$}

A unidade sísmica $U_{3}$ é preservada apenas na porção distal da área, a partir da atual isóbata de 48 m (Figs. 3 a 5). Apresenta também variabilidade lateral de espessura no sentido leste-oeste, podendo variar entre cerca de $10 \mathrm{~m}$ até seu total desaparecimento em zonas de canalização da superfície $S_{3}$ (topo desta unidade; Fig. 3). $S_{3}$ representa na área de estudo a superfície erosiva de maior irregularidade.

A unidade $\mathrm{U}_{3}$ mantém uma homogeneidade em termos de fácies sísmicas em toda área, caracterizada predominantemente por refletores plano-paralelos contínuos, interpretada como indicativa de deposição marinha (fácies $f_{3}$ a; Figs. 2 a 4). Em sua base, a unidade apresenta localmente fácies de preenchimento fluvial $\left(f_{2}\right.$ a; Figs. 2 e 3$)$.

\section{Unidade sísmica $\mathrm{U}_{4}$}

A unidade sísmica $\mathrm{U}_{4}$ encontra-se preservada em toda área de estudo como a unidade de maior espessura (Figs. 3, a 5).

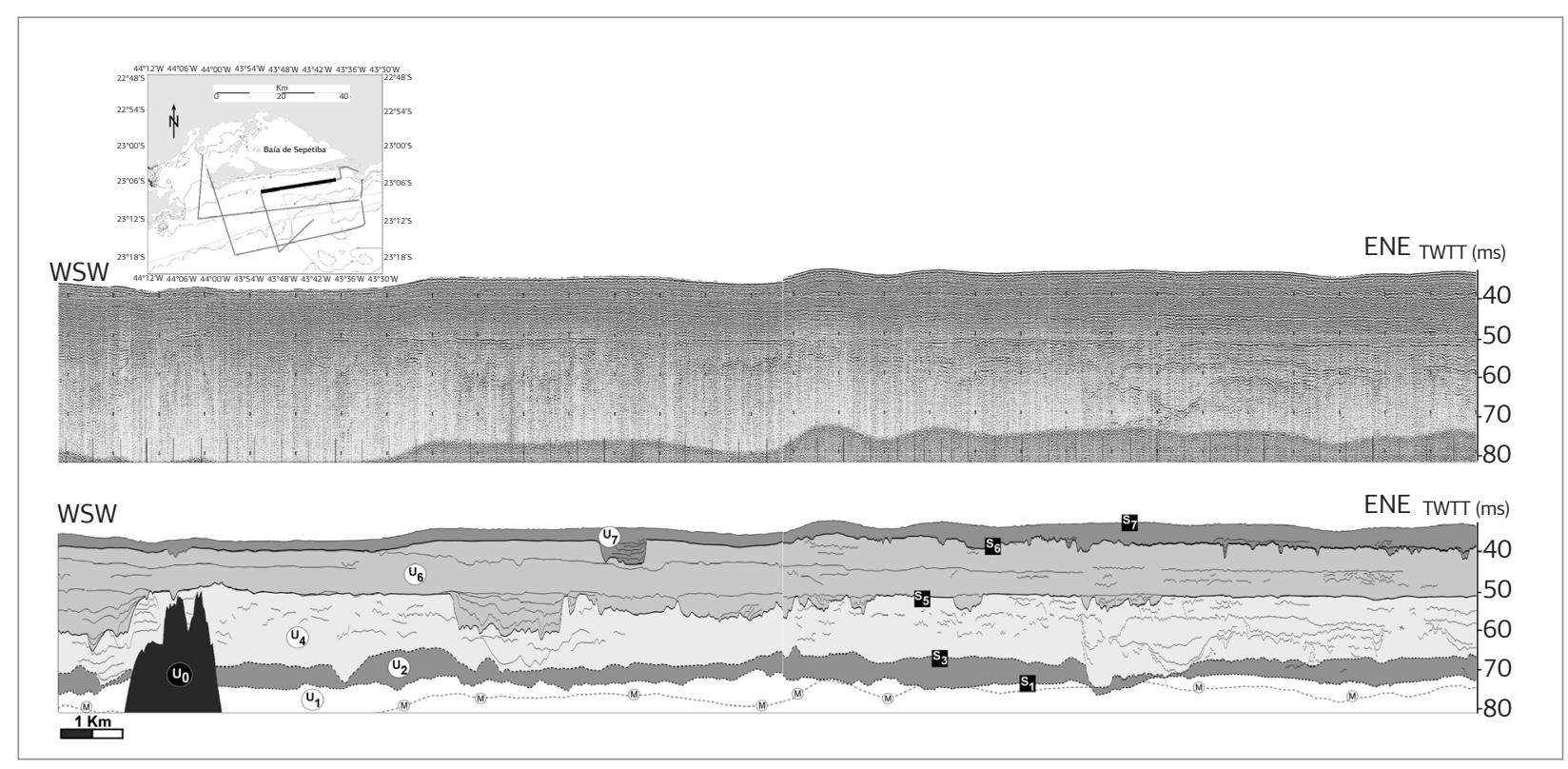

Figura 5. Perfil sísmico com orientação paralela à costa, localizado na porção central proximal da área de estudo (acima), paralelo à Restinga da Marambaia, e esquema interpretativo ilustrando as unidades sísmicas identificadas na área (abaixo). U: unidade; f: fácies. 
$\mathrm{Na}$ parte distal da área, a unidade apresenta menores espessuras, $-12-15 \mathrm{~m}$, com predomínio de fácies indicativas de múltiplos cortes e preenchimentos de canais estuarinos.

A base da unidade é caracterizada por superfície marcada por grandes zonas erosivas (superfície $S_{3}$ ), com presença local de fácies de preenchimento de canal, de até $-15 \mathrm{~m}$ de profundidade, e com largura de até $-450 \mathrm{~m}$, interpretados como canais fluviais (fácies $f_{2}$ a, Figs. 2 e 3). Essa fácies é sobreposta estratigraficamente por uma sucessão de feiçôes canalizadas, de $-12-15 \mathrm{~m}$ de espessura, com evidências de múltiplas superfícies de erosão e feiçôes de preenchimento, interpretadas como indicativas de um ambiente energético com sucessivas migraçóes laterais de sistema fluvio-estuarino (fácies $f_{4}$ a; Figs. 2 e 3). Localmente, essa unidade apresenta ainda: (a) fácies plano-paralelas descontínuas suavizando o preenchimento de canal, interpretadas como fácies deposicionais de ambientes mais calmos, semifechados, como o ambiente de boca de estuário (fácies $f_{4}$ b, Figs. 2 e 3); (b) fácies tabulares com reflexóes internas oblíquas (fácies $f_{5}$, Figs. 2 e 3 ) interpretadas como barras arenosas estuarinas; e (c) fácies caracterizadas por refletores internos divergentes preenchendo amplas canalizaçóes (fácies $f_{6}$; Figs. 2 e 3 ).

$\mathrm{Na}$ parte distal da área, seu topo é marcado por uma superfície suave, regionalmente plana, sem evidências sísmicas de erosão (superfície $S_{4}$; Fig. 3). No entanto, na porção proximal da área, grandes zonas de canalizaçáo erodem a unidade $\mathrm{U}_{5}$ sobreposta, formando canalizaçôes no topo da unidade $\mathrm{U}_{4}$ (Fig. 4). Nesta porçấo proximal, observa-se ligeiro aumento de espessura $(-18 \mathrm{~m})$ e um predomínio de refletores descontínuos com presença de múltiplas canalizaçôes estuarinas, indicando possivelmente canais de marés internos a um sistema estuarino semifechado (Fig. 5).

\section{Unidade sísmica $\mathrm{U}_{5}$}

A unidade sísmica $\mathrm{U}_{5}$ é preservada apenas a partir de profundidades atuais de $-35 \mathrm{~m}$ (Figs. 3 e 4), chegando a $\sim 8-10 \mathrm{~m}$ de espessura distalmente. Essa unidade sísmica apresenta em sua área de ocorrência grande homogeneidade de fácies sísmica, sendo caracterizada por refletores internos plano-paralelos contínuos, interpretados como fácies indicativa de deposição marinha (fácies $f_{3}$ b; Figs. 2 e 3). Seu topo é definido por uma superfície erosiva marcada por uma série de incisōes canalizadas (superfície $S_{5}$; Figs. 3 e 4).

\section{Unidade sísmica $\mathrm{U}_{6}$}

A unidade sísmica $\mathrm{U}_{6}$ é preservada em toda área de estudo como um prisma sedimentar que se adelgaça em direção à plataforma, apresentando proximalmente $\sim 10 \mathrm{~m}$ de espessura e, distalmente, apenas $-2-3 \mathrm{~m}$ (Figs. 3 e 4 ).

A base da unidade é caracterizada por fácies sísmicas de preenchimento de canais de $-150-1900$ de largura e
$-5-15 \mathrm{~m}$ de profundidade, interpretados como canais de maré $\left(f_{2}\right.$ b; Figs. 2 a 5$)$. Essas feiçôes de preenchimento de canal variam desde fácies indicativas de migração lateral (Figs. 3 e 4) a fácies de preenchimento de colmatação de canal isolado (Figs. 3 e 5). A porção superior da unidade é caracterizada por refletores plano-paralelos, constituindo estratos tabulares lateralmente contínuos, interpretados como deposiçáo em ambiente marinho (fácies $f_{3}$ b; Figs. 2 a 5). O topo da unidade é limitado por uma superfície plana e suave, que representa na porção distal da área de estudos a própria superfície do fundo marinho (superfície $S_{6}$; Figs. 3 e 4).

\section{Unidade sísmica $\mathrm{U}_{7}$}

A unidade sísmica $U_{7}$ representa a unidade topo da sucessão estratigráfica. Essa unidade é reconhecida apenas entre a costa e a porção central da área, a $-45 \mathrm{~m}$ de profundidade, sob forma de uma cunha sedimentar que se adelgaça em direção ao mar (Fig. 4). Sua superfície topo (superfície $S_{7}$ ) representa o fundo submarino na sua área de ocorrência. Sua base, a superfície $S_{6}$, apresenta localmente esculpimento de canais $\left(f_{2}\right.$ b, Figs. 2 e 5$)$. Desse modo, a estratigrafia interna da unidade $U_{7}$ se assemelha à da unidade $\mathrm{U}_{6}$ : sua base é caracterizada por fácies sísmicas de preenchimento de canais de $-100-800 \mathrm{~m}$ de largura e $-1,5-5,5 \mathrm{~m}$ de profundidade, interpretados como canais de maré preservados $\left(f_{2}\right.$ b, Fig. 2$)$; enquanto sua porção de topo é caracterizada por refletores plano-paralelos, constituindo estratos tabulares lateralmente contínuos, interpretados como refletindo deposição em ambiente marinho (fácies $f_{3}$ b; Figs. 2 e 5 ).

\section{DISCUSSÃO}

Nos subitens abaixo são apresentadas proposiçôes de idade, de ciclicidade deposicional e de possível significado glacioeustático das unidades sísmicas $U_{1}-U_{7}$ definidas e descritas na plataforma continental rasa à frente da Restinga da Marambaia (RJ).

\section{Correlação cronoestratigráfica das unidades sísmicas}

$\mathrm{Na}$ plataforma continental fluminense, não há dados cronoestratigráficos disponíveis a partir de testemunhagem que permitam a datação do topo da seção sedimentar da plataforma rasa. Comumente, a testemunhagem contínua na província das plataformas continentais brasileiras e nas bacias marginais como um todo tem sido executada pela indústria de petróleo por meio de poços de sondagem exploratória, nos quais o intervalo estratigráfico 
Pleistoceno-Holoceno é geralmente descartado e não amostrado para datação bioestratigráfica por se tratar de janela estratigráfica de pouco interesse para hidrocarbonetos. Desse modo, a coluna sedimentar imageada nos cerca de $70 \mathrm{~ms}$ de espessura (duplo tempo) na plataforma continental rasa da área de estudos nunca foi amostrada por testemunhagem direta.

Os poucos dados disponíveis sobre a idade dessa coluna sedimentar advêm de correlaçôes de Estratigrafia de Sequências. Maia et al. (2010) e Reis et al. (no prelo) investigaram a seção sedimentar rasa da plataforma continental fluminense na porção nordeste da bacia de Santos, onde identificaram paleosuperfícies de exposição total da plataforma continental à erosão subaérea, a partir das quais definiram uma série de sequências deposicionais (chamadas de Sq1-Sq5) nos primeiros $300 \mathrm{~ms}$ de espessura sedimentar. Por meio da correlação com dados cronoestratigráficos de um poço localizado na bacia de Campos (disponibilizado pelo Banco de Dados de Exploração e Produção-Agência Nacional do Petróleo - BDEP-ANP), os autores puderam indicar que a superfície erosiva basal identificada, chamada de S1, correspondia ao chamado "Marco P" (datado de aproximadamente 0,5 Ma na bacia de Campos, por Silva 1992). Esses dados permitiram uma estimativa de idade Pleistoceno Médio-Holoceno para a coluna sedimentar repousando acima da superfície S1. Além disso, a correlação entre a interpretação dos dados sísmicos e cronoestratigráficos com curvas globais de variaçóes eustáticas, baseadas em variaçóes isotópicas de $\delta^{18} \mathrm{O}$, permitiu ainda aos autores sugerir que as quatro primeiras sequências reconhecidas acima de S1 (sequências Sq1-Sq4) registram essencialmente sequências regressivas de quarta ordem, refletindo deposição durante ciclos glacioeustáticos de cerca de 100 - 120 ka de duração, relacionados a mudanças cíclicas do padrão orbital de excentricidade terrestre (ciclos de Milankovitch), durante os últimos 450 - $500 \mathrm{ka}$. A última sequência, chamada de Sq5, foi interpretada como correspondendo à deposição ocorrida na plataforma continental desde a última deglaciação, ou seja, depósitos de idade Pleistoceno Tardio-Holoceno (últimos 22 - $18 \mathrm{ka}$ ) que se depositaram sobre a última superfície de erosão e ampla exposição da plataforma continental, esculpida durante a última glaciação ocorrida entre os estágios isotópicos marinhos MIS 5 e MIS $2(-130-18$ ka A.P.).

O cruzamento da base de dados de alta resolução utilizada no presente trabalho, com as interpretaçóes sísmicas dos perfis de Maia et al. (2010) e Reis et al. (no prelo) que cruzam a área de estudos (dados sísmicos Geomar e Rio Costa I ilustrados na Figura 1), permitiram as seguintes correlaçóes: a superfície erosiva denominada de $S_{1}$ (no presente trabalho) correlaciona-se estratigraficamente à superfície de exposição total da plataforma ocorrida entre os estágios isotópicos marinhos MIS 7 e MIS 6 esculpida entre -240 e 130 ka (Fig. 6); a superfície erosiva denominada de $S_{3}$ (no presente trabalho) relaciona-se estratigraficamente à superfície de exposiçáo total da plataforma ocorrida entre os estágios isotópicos marinhos MIS 5 e MIS 2, formada entre -130 e $18 \mathrm{ka}$ (Fig. 6).

Nesse contexto, as superfícies $S_{1}$ e $S_{3}$ são interpretadas como sendo ao mesmo tempo superfícies de regressão máxima (Maximum Regression Surface (MRS), no sentido de Catuneanu 2006) e superfícies-limite de sequências deposicionais, ou Sequence Boundary ((SB) no sentido de Hunt \& Tucker 1992, Plint \& Nummedal 2000). Essas superfícies são fortemente erosivas e com presença de canalizaçôes fluviais, feiçóes que sugerem a atuação de processos erosivos relacionados a longos períodos de exposição subaérea da plataforma continental durante períodos de queda relativa do nível do mar, resultando em discordâncias de escala regional (Fig. 6). Assim:

- A unidade sísmica $U_{1}$ foi correlacionada à deposição ocorrida entre aproximadamente -230 - 250 e $130-140 \mathrm{ka}$ A.P. (Fig. 6), correspondendo à sequência Sq3 de Maia et al. (2010) e de Reis et al. (no prelo);

- As unidades sísmicas $\mathrm{U}_{2}$ e $\mathrm{U}_{3}$ podem ser agrupadas numa sequência deposicional de quarta ordem, depositada entre os estágios isotópicos marinhos 6 e 2 (entre $\sim 130-140$ e $30-20$ ka A.P.; Fig. 6), representando a sequência Pleistoceno Superior. Essa sequência corresponde, dessa forma, à sequência Sq4 de Maia et al. (2010) e Reis et al. (no prelo);

- As unidades sísmicas $\mathrm{U}_{4-} \mathrm{U}_{7}$ são estratigraficamente relacionáveis à deposição ocorrida desde a última deglaciação, correspondendo assim à deposição sedimentar ocorrida na plataforma continental desde o início da última transgressão marinha, de idade Pleistoceno Tardio-Holoceno, iniciada globalmente há $-22-18$ ka (Fig. 7). Essas unidades correspondem dessa forma à sequência $\mathrm{Sq} 5$ de Reis et al. (no prelo), assim denominadas por refletirem a deposição sedimentar em regime transgressivo e de mar alto de uma sequência deposicional ainda em formação.

\section{As sequências deposicionais e o significado glacioeustático de suas unidades sísmicas internas}

As unidades sísmicas $\mathrm{U}_{1}, \mathrm{U}_{2}, \mathrm{U}_{3}, \mathrm{U}_{4}, \mathrm{U}_{5}, \mathrm{U}_{6} \mathrm{e} \mathrm{U}_{7}$ foram agrupadas numasucessão de duassequências deposicionais principais de $4^{a}$ ordem (Sq3, Sq4) e em depósitos transgressivos e de mar alto (Sq5), desenvolvidos pela alternância de períodos de exposição total e de afogamento (transgressão) da plataforma continental, relacionados à repetição de ciclos glacioeustáticos de 

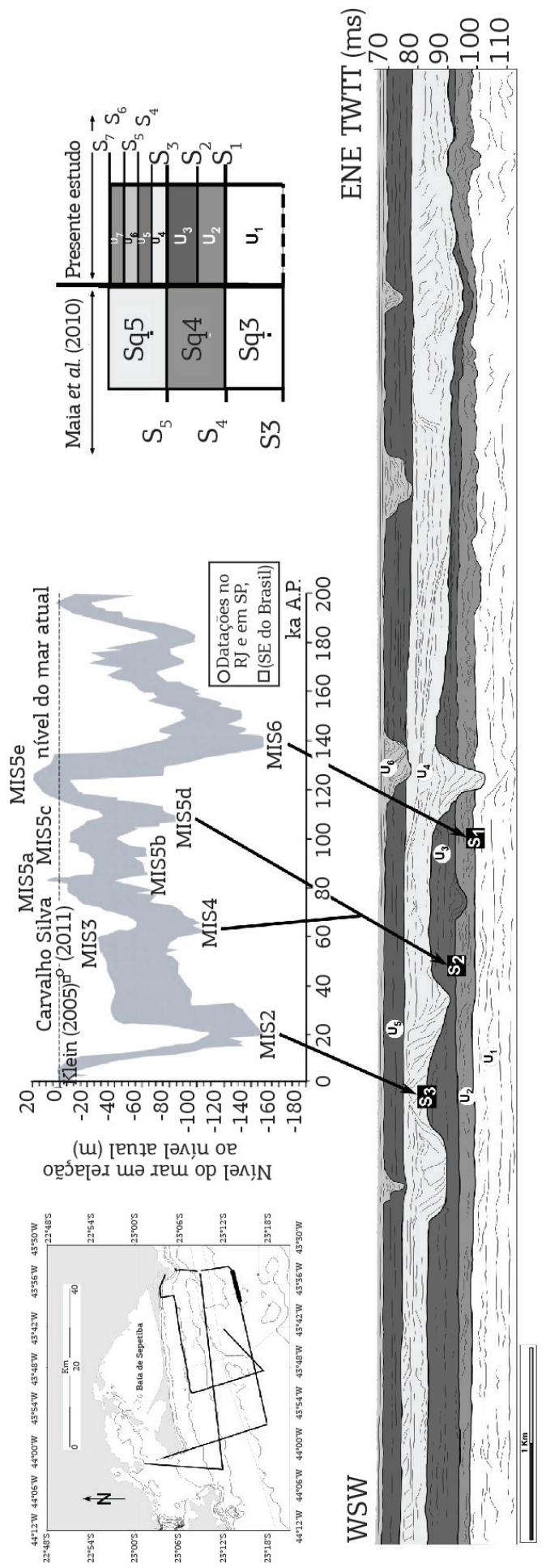

Figura 6. Esquema interpretativo de perfil sísmico com orientação paralela à costa, ilustrando as sequências deposicionais Sq3-Sq5 reconhecidas, separadas pelas superfícies $\mathrm{S}_{1}, \mathrm{~S}_{2}$ e $\mathrm{S}_{3}$, e, em destaque, a correlação dessas superfícies com os estágios isotópicos marinhos. $O$ envelope das curvas isotópicas de variações eustáticas globais é uma compilação de Rabineau et al. (2006), baseada na razão isotópica de $\delta^{18} 0$ calibradas pela datação de feições morfológicas, diagenéticas e orgânicas em plataformas continentais entre os estágios isotópicos marinhos 2 e 6. O círculo e o quadrado próximos ao nível do mar atual representam datações correlacionáveis ao subestágio isotópico marinho 3 (MIS 3) próximas à área de estudos. Acima, à direita, encontra-se um esquema com as unidades $\mathrm{U}_{1-} \mathrm{U}_{7}$ e suas superfícies limitantes $\mathrm{S}_{1}-\mathrm{S}_{7}$ correlacionadas com as sequências Sq3-Sq5 de Maia et al. (2010). U: unidade; S: superfície; MIS: Estágios Isotópicos Marinhos. 
100 - 120 ka de duração. No entanto, as unidades sísmicas $U_{1}, U_{2}, U_{3}, U_{4}, U_{5}, U_{6}$ e $U_{7}$ compóem uma sucessão vertical e lateral de fácies sísmicas, assim como exibem superfícies internas de diferentes significados estratigráficos, que refletem variaçóes ambientais dos sistemas deposicionais da plataforma rasa.

Uma pergunta que naturalmente se coloca é: o que tais fácies sísmicas diferenciadas em cada sequência representam em termos de variaçôes ambientais e o que elas indicam sobre o registro e a evolução dinâmica dos sistemas fluvio-estuarinos da regiáo de Sepetiba/RJ?

\section{A sequência deposicional Sq3 na área de estudo}

A sequência deposicional Sq3 (Fig. 6) não é totalmente imageada na área em razão de limitaçôes de penetração do sinal acústico; apresenta-se, contudo, como sismicamente homogênea, caracterizada pela predominância de fácies estuarinas distais, hoje ainda preservadas na plataforma continental rasa $\left(f_{1}\right.$ a; Fig. 2$)$. A preservação dessas fácies aponta para a existência de sistemas estuarinos na regiáo, correlatos à atual bacia de drenagem e sistema estuarino de Sepetiba, já desde pelo menos há $\sim 250$ ka A.P.

\section{A sequência deposicional Sq4 na área de estudo}

$A$ sequência deposicional $\mathrm{Sq} 4$ apresenta-se verticalmente diferenciada, sendo composta pelas unidades sísmicas $\mathrm{U}_{2}$ e $\mathrm{U}_{3}$, separadas pela superfície $\mathrm{S}_{2}$ (Fig. 6). Enquanto a unidade sísmica basal $U_{2}$ foi interpretada como o registro de fácies estuarinas distais $\left(f_{1}\right.$ b; Fig. 2$)$, a unidade sísmica superior $U_{3}$ foi interpretada como indicativa de deposição marinha $\left(f_{3}\right.$ a; Fig. 2). A superfície $S_{2}$ que limita as duas unidades sísmicas é de natureza claramente erosiva, apresentando, inclusive, o esculpimento de alguns canais fluviais de pequena dimensão (Fig. 6). Esses atributos sísmicos indicam que tal horizonte estratigráfico representa uma superfície de exposição ao menos parcial da plataforma continental rasa da área de estudos, pelo menos até a atual profundidade de $-50 \mathrm{~m}$.

A correlação entre este conjunto de elementos estratigráficos (presença e natureza da superfície $\mathrm{S}_{2}$ e fácies sísmicas das unidades $\mathrm{U}_{2}$ e $\mathrm{U}_{3}$ ) e curvas globais de variaçôes eustáticas (Fig. 6) indica que a sequência Sq4 pode ser interpretada como sendo composta por subsequências relacionadas a variaçôes de tendência de movimentos eustáticos induzidos por ciclos glaciais de ordem inferior, de $-20-40 \mathrm{ka} \mathrm{de} \mathrm{du-}$ ração: a base da sequência (unidade $\mathrm{U}_{2}$ ) é aqui interpretada como representando a preservação de uma subsequência transgressiva estuarina depositada entre os estágios MIS 6 e MIS 5e (Fig. 6); o horizonte $S_{2}$ é interpretado como uma superfície regressiva (amalgamação das superfícies relacionadas aos subestágios MIS 5d e MIS 4; Fig. 6); e, finalmente, o topo da sequência (unidade $\mathrm{U}_{3}$ ) pode ser interpretado como parte de uma sequência transgressiva marinha preservada, relacionada ao afogamento da plataforma continental durante o subestágio MIS 3 (Fig. 6). A diferença ambiental entre a presença de uma sequência transgressiva estuarina, na base, e uma sequência transgressiva marinha, no topo da sequência $\mathrm{Sq} 4$, pode ser explicada pela maior rapidez do aquecimento climático relacionado ao subestágio isotópico MIS 3 (curto período de aquecimento na trajetória de glaciação durante o Pleistoceno Superior). Essa situação pode ter provocado uma transgressão marinha de alta taxa de elevação relativa do nível do mar, com o consequente rápido afogamento da plataforma, o que teria impedido o desenvolvimento de sequências estuarinas na atual plataforma rasa e sua formação provavelmente apenas na altura da atual planície fluvial do fundo da Baía de Sepetiba.

Na realidade, há estudos na costa brasileira, em localidades próximas à área de estudo, que indicam a ocorrência de posiçáo de nível do mar na margem sudeste brasileira bem mais alto que o esperado para o estágio isotópico MIS 3, como já apontado por Mahiques et al. (2010), cuja posição de nível de mar em várias regiôes do globo está situada a até $-75 / 85 \mathrm{~m}$ abaixo do atual. Klein (2005), por exemplo, reportou a existência de depósitos marinhos afogados, representados por camadas de lamas localizadas a $-7 \mathrm{~m}$ abaixo do nível marinho atual, na região de São Sebastião/SP, próxima à Baía de Sepetiba, datados por radiocarbono em $-39.500 \mathrm{cal}$ anos A.P. (Fig. 6). Mais recentemente, Carvalho Silva (2011) também datou em -40 - 46 ka A.P. amostras de conchas e fragmentos vegetais (por AMS ${ }^{14} \mathrm{C}$ ) encontrados em uma camada lamosa basal presente sob as camadas arenosas da planície costeira de Maricá (Fig. 6). Essa datação é representativa de um paleosistema ilha barreira-laguna formado durante o Pleistoceno Superior, parcialmente preservado a cerca de 8 metros abaixo da superfície da planície costeira atual. Interpretamos assim que ambas as dataçôes testemunham posição de nível do mar durante o estágio isotópico MIS 3 próximo, ou mesmo acima, da posição de nível do mar atual na região da área de estudos (Fig. 6).

Os resultados sobre o significado glacioeustático da sequência deposicional Sq4 na plataforma rasa da área de estudos são compatíveis com a arquitetura estratigráfica apontada por Reis et al. (no prelo) para a mesma sequência na escala da plataforma continental fluminense. Para esses autores, a porção proximal da sequência $\mathrm{Sq} 4$ na plataforma fluminense registra a preservação de unidades transgressivas relacionadas aos mesmos subestágios isotópicos. Os componentes regressivos da sequência Sq4 se depositaram e são preservados apenas na porção de plataforma mais externa, sob forma de prismas de regressão forçada. 


\section{A sequência Sq5 na área de estudos}

A arquitetura interna da sequência Sq5 oferece o maior grau de detalhamento e a maior resolução relativa de fácies e elementos estratigráficos identificáveis, quando comparada à arquitetura interna das sequências deposicionais Sq3 e Sq4 na área de estudo (Fig. 6). O empilhamento vertical das unidades sísmicas $\mathrm{U}_{4}-\mathrm{U}_{7}$ (Figs. 4 e 6) testemunha grandes variaçôes ambientais, como também mudanças significativas de regimes energéticos desde o início de sua deposição sedimentar.

\section{Unidades sísmicas $\mathrm{U}_{4}$ e $\mathrm{U}_{5}$}

A base da sequência Sq5, composta pela unidade sísmica $U_{4}$, apresenta fácies de preenchimento de canais fluviais em sua porção mais basal (fácies $f_{2}$ b; Figs. 2 e 6), esculpidos sobre a superfície $S_{3}$, que representa o limite basal da sequência $(S B)$. Essas feiçóes de colmatação fluvial na base da unidade $\mathrm{U}_{4}$ apontam para uma estabilizaçấo de queda de nível de base, ou mesmo uma trajetória já ascendente de nível de mar, durante a deposição dessas feiçôes de preenchimento. Pela posição desses canais fluviais preenchidos, localizados na plataforma interna fluminense (até cerca de 50 - $60 \mathrm{~m}$ de lâmina d'água atual), interpreta-se a deposição intracanal como representando unidades transgressivas de idade Holoceno. Na ausência de curvas na área de estudos indicando posiçôes de nível do mar abaixo da atual durante a última deglaciação, a atribuição de idade baseia-se na correlação com dados globais de variaçóes eustáticas, como as curvas de Bard et al. (1990), tomadas como uma aproximaçáo, propostas por meio de medições de isótopos estáveis em corais na região de Barbados (Fig. 7). Essas curvas indicam que, no início do Holoceno ( $-11 \mathrm{ka})$, o nível global do oceanos encontrava-se em torno de -60/-70 m. Essa interpretação é também compatível com estudos de Reis et al. (no prelo), realizados na escala regional da plataforma continental adjacente à Baía de Sepetiba, que mostram, por meio $\mathrm{da}$ arquitetura interna da sequência $\mathrm{Sq} 5$, que unidades sedimentares transgressivas do Pleistoceno Tardio (início da última transgressão) foram depositadas mais distalmente na atual plataforma externa (além dos $-100 \mathrm{~m}$ atuais).

A continuação da deposição $\mathrm{da}$ unidade $\mathrm{U}_{4}$ se dá por uma sucessão de feiçôes canalizadas com evidências de múltiplas fases de erosão e preenchimento (fácies $f_{4}$; Figs. 2 e 6), ilustrando sucessivas migraçóes laterais de um sistema fluvio-estuarino. $\mathrm{O}$ topo da unidade apresenta ainda uma interdigitação de fácies de preenchimento de boca de estuário (fácies $f_{4}$ b; Figs. 2 e 6 ) e de fácies representativas da presença de barras arenosas estuarinas (fácies $f_{5}$; Figs. 2 e 6), sugerindo a implantação de fácies regressivas na área. Essas fácies regressivas presentes no topo da unidade $\mathrm{U}_{4}$

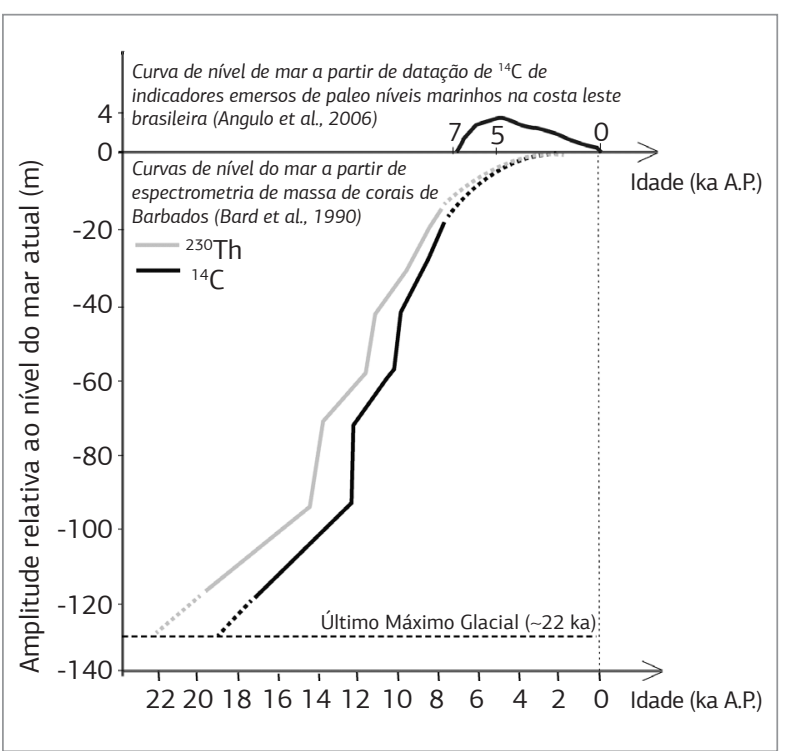

Figura 7. Curva composta de variação do nível do mar para os últimos $22 \mathrm{ka}$ (deglaciação Pleistoceno Tardio-Holoceno). A curva de posição de nível do mar para os últimos $7 \mathrm{ka}$ (acima do atual) é baseada em dados da curva proposta por Angulo et al. (2006) para o litoral sudeste brasileiro. A curva para posições de nível do mar abaixo do atual é baseada em medições de isótopos estáveis em corais na região de Barbados (Bard et al., 1990).

(fácies $f_{4}$ b e $f_{5}$; Figs. 2 e 6 ) indicam a implantação temporária de um ambiente estuarino mais protegido (boca de estuário), provavelmente induzido por variaçóes temporárias na relação entre a taxa de elevação relativa do nível do mar e a taxa de aporte sedimentar. Ainda num contexto transgressivo da sequência $\mathrm{Sq}$ 5, a unidade sísmica $\mathrm{U}_{5}$ testemunha a implantação de um ambiente marinho aberto, sugerido pela deposição de unidades sedimentares lateralmente contínuas, homogeneamente distribuídas na área de estudos (fácies $f_{3}$ a; Figs. 2 e 6 ).

Os principais conjuntos de fácies que compóem as unidades sísmicas $\mathrm{U}_{4}$ e $\mathrm{U}_{5}$ (estuarino na base e marinho no topo) atestam o caráter e a tendência transgressiva da sequência Sq5, no contexto de afogamento de um sistema fluvio-estuarino em porçōes de costa aberta (na base), passando para um ambiente marinho aberto no topo da sucessão sedimentar. Essa sucessão de fácies sísmicas é compatível com o empilhamento estratigráfico desenvolvido num contexto glacioeustático de rápido afogamento marinho, como o esperado para a deposição transgressiva durante o Holoceno Inferior à Médio, que ocorre segundo curvas de variaçóes glacioeustáticas mundiais, até $-8-7$ ka A.P. (época em que a transgressão inicia uma trajetória de desaceleração; Fig. 7). 
Diminuiçôes temporárias na taxa de elevação do nível do mar durante a deglaciaçáo são apontadas em curvas globais disponíveis, como a curva proposta por Bard et al. (1990) ilustrada na Fig. 7.

Como aspectos relevantes da sequência Sq5, é importante ainda ressaltar que a presença de incisóes fluviais na base das unidades sedimentares (correlacionadas à exposição da plataforma durante o estágio isotópico marinho 2) e a preservaçáo do registro de um sistema fluvio-estuarino holocênico na plataforma interna testemunham mudanças de nível de base na região e a atuação de um sistema fluvial bem desenvolvido, correlato à atual bacia de drenagem presente a montante da Baía de Sepetiba.

\section{Unidades sísmicas $\mathrm{U}_{6}$ e $\mathrm{U}_{7}$}

As unidades sísmicas $\mathrm{U}_{6}$ e $\mathrm{U}_{7}$ (topo da sucessão estratigráfica imageada) representam unidades-chave para a compreensão da implantação e configuração da Baía de Sepetiba como um ambiente estuarino semifechado, assim como para a compreensão da evolução hidrodinâmica da região. Ambas as unidades apresentam forma externa de cunha sedimentar e têm suas bases caracterizadas pela preservação de canais de marés $\left(f_{2}\right.$ b; Figs. 2 e 6$)$. Já a parte superior das unidades é caracterizada por estratos tabulares lateralmente contínuos, testemunhando a implantação de um ambiente marinho de costa aberta na área (fácies $f_{3}$ b; Figs. 2 e 6 ).

Uma diferença fundamental entre as unidades $U_{6}$ e $U_{7}$, no entanto, reside na sua área de ocorrência: enquanto a unidade basal $\mathrm{U}_{6}$ estende-se por toda a área até porçóes mais distais da plataforma, a unidade $\mathrm{U}_{7}$ acunha-se em direção ao mar, nas proximidades da atual isóbata de $45 \mathrm{~m}$, evidenciando deposição mais restrita e proximal (Fig. 4). Outra diferença é que os canais de maré preservados na base das unidades apresentam diferentes dimensóes: os canais de maré presentes na base da unidade $\mathrm{U}_{6}$ variam de $-150-450 \mathrm{~m}$ de largura e profundidade de $-8 \mathrm{~m}$ (Fig. 5), enquanto os estratigraficamente superiores preservados na base da unidade $U_{7}$ apresentam, em geral, largura de $-50-150 \mathrm{~m}$ e profundidade de $-2 \mathrm{~m}$ (Fig. 5). Esse conjunto de elementos estratigráficos foi interpretado como compondo unidades sedimentares desenvolvidas ainda em um regime transgressivo, contudo, em um cenário de desaceleração de elevação relativa do nível do mar e de afogamento mais lento da plataforma interna. Essas inferências e interpretaçóes devem-se à existência de canais de maré nas unidades sísmicas analisadas, fato que pressupóe uma série de implicações arquiteturais e dinâmicas na evolução do sistema fluvio-estuariano da região de Sepetiba, como:

- A construção de barreiras arenosas em contexto eminentemente transgressivo, possibilitada provavelmente por um cenário de desaceleração de elevação do nível do mar, como o que acontece a partir de -8 ka A.P., com posição de nível de mar global de -30 - $20 \mathrm{~m}$ (Fig. 7);

- A configuração de ilhas-barreira segmentadas por inúmeros canais de maré, como aquelas que isolam parcialmente estuários onde, independentemente da amplitude de maré, há correntes de maré de alta velocidade por causa do estreitamento do fluxo (Dalrymple et al. 1992);

- A formação de ilhas-barreira segmentadas já em porções mais distais que a da atual Restinga da Marambaia e sua contínua erosão e migração em direção ao continente durante a transgressão. Essa migração é indicada pelo fato de a unidade sísmica $\mathrm{U}_{6}$ (preservada em toda área de estudo) apresentar canais de maré mais distais, preservados em posição estratigráfica mais inferior, recobertos por estratos marinhos tabulares e amplamente distribuídos. No topo dessa unidade, são re-esculpidos canais de maré mais proximais, e estratigraficamente superiores, preservados na base da unidade $\mathrm{U}_{7}$, finalmente recobertos por sedimentação de ambiente marinho aberto (topo da unidade $\mathrm{U}_{7}$, Fig. 5). É importante ressaltar que as ilhas-barreira descontínuas não foram preservadas no registro estratigráfico, uma vez que se trata de feiçôes efêmeras, construídas e constantemente destruídas durante a transgressão; os canais de maré preservados são, no entanto, a prova da existência das ilhas-barreira;

- Perfis sísmicos em posiçáo strike e dip, próximos à atual Restinga da Marambaia, mostram que a parte superior da unidade $\mathrm{U}_{7}$ é constituída por um prisma progradante, de $-12 \mathrm{~m}$ de espessura, que se adelgaça em direçáo à plataforma, até desaparecer próximo à isobata de $22 \mathrm{~m}$, e é estratigraficamente correlato à deposição da atual restinga (Fig. 8). O topo da unidade $\mathrm{U}_{7}$ registra, desse modo, a passagem de um regime deposicional transgressivo para um regime regressivo, cuja superfície-limite que separa os canais de maré dos estratos progradantes do prisma sotoposto (Fig. 8) pode ser interpretada como a superfície de afogamento máximo na área (MFS: Maximum Flooding Surface, no sentido de Catuneanu 2006). Essa superfície pode corresponder à posição de transgressão máxima na regiâo, datada por Martin et al. (2003) e Angulo et al. (2006) em $\sim 5,8$ ka A.P. (Fig. 7).

A implantação do prisma regressivo testemunha também o fechamento dos canais de maré e de múltiplos canais de comunicação entre o estuário e a plataforma interna adjacente à frente da restinga; sinaliza finalmente que a configuração da Restinga da Marambaia como corpo arenoso contínuo entre a Barra de Guaratiba e a "Ilha” da Marambaia (Fig. 1) representa uma configuraçáo arquitetural só atingida após o máximo transgressivo na área, por volta de $\sim 5,8$ ka A.P. 


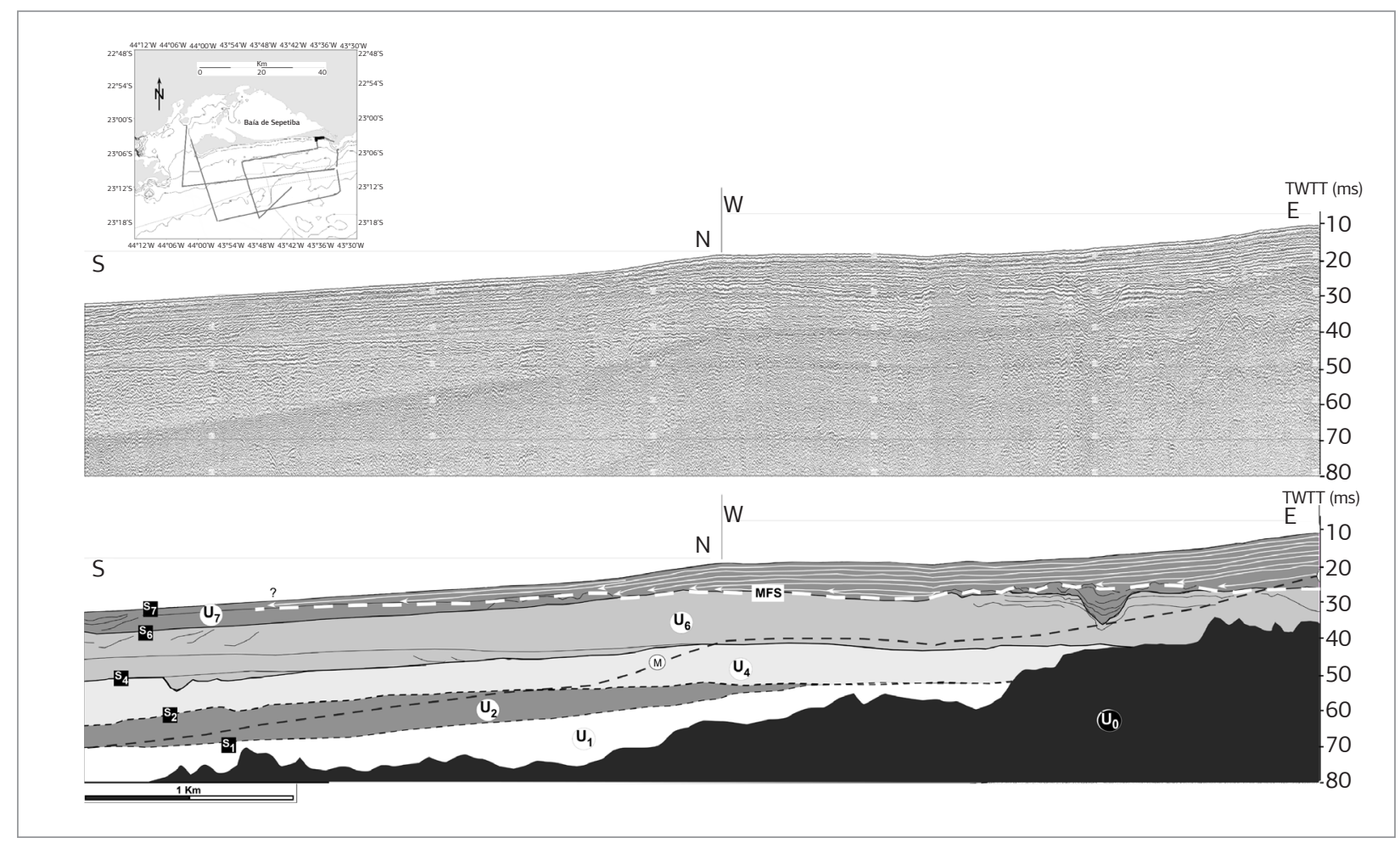

Figura 8. Perfil sísmico de orientação transversal à costa, localizado na porção nordeste mais proximal da área de estudo, junto à Restinga da Marambaia, ilustrando um prisma progradante estratigraficamente correlato à deposição da atual restinga (setas brancas). A linha branca tracejada representa a superfície de inundação máxima (MFS: Maximum Flooding Surface). U: unidade; S: superfície; M: reflexão múltipla.

\section{CONCLUSÕES}

Este trabalho permitiu a investigação e proposição de um arcabouço estratigráfico para as sequências sísmicas que compóem o topo do registro sedimentar $(-70 \mathrm{~ms})$ da plataforma continental rasa à frente da Restinga da Marambaia, até cerca de $60 \mathrm{~m}$ de lâmina d'água atual.

Os resultados da análise sísmica permitiram a proposição de cenário paleogeográfico envolvendo o atual sistema estuarino da Baía de Sepetiba, integrando detalhes do registro estratigráfico da plataforma rasa à evolução da configuração do sistema fluvio-estuarino da Baía de Sepetiba. A Fig. 9 abaixo ilustra, de forma simplificada e cronológica, a implantação e as modificaçôes da configuração geográfica do sistema estuarino de Sepetiba, baseadas na sucessão estratigráfica observada na plataforma rasa adjacente e na ciclicidade deposicional proposta para o período Pleistoceno Tardio-Holoceno (últimos $-22-18 \mathrm{ka}$ ) na área de estudos:

- A história continental da área (pré-afogamento transgressivo) é sismica e estratigraficamente registrada pela presença de uma rede de drenagem fluvial atuante até o máximo regressivo, que data globalmente de $-22-18 \mathrm{ka}$, esculpida no topo da sequência Sq4 (Fig. 6). A preservação de uma rede de canais fluviais na plataforma rasa mostra a atuação de um sistema fluvial desenvolvido, correlato à bacia de drenagem a montante, que hoje alimenta a Baía de Sepetiba. A presença desses canais à frente da atual Restinga da Marambaia mostra também que o embasamento cristalino mais raso próximo à restinga (Figs. 5 e 8) não foi impeditivo para a passagem da rede fluvial da regiáo de Sepetiba para a plataforma adjacente. A posição estratigráfica e topográfica do embasamento cristalino observado nos perfis sísmicos é ilustrativa de que, embora o alinhamento Ponta de Guaratiba - Restinga-Ilha da Marambaia (Fig. 1) represente a borda flexural do Graben da Guanabara que forma estruturalmente a Baía de Sepetiba (Zalán \& Oliveira 2005), tal estruturação não resultou em porçôes cristalinas suficientemente elevadas a ponto de impedir a passagem e o escoamento da rede fluvial que alimenta a baía para a plataforma rasa adjacente, quando da queda de nível de base durante a glaciação do Pleistoceno Superior $(-130-18$ ka) (Fig. 9A);

- A rápida elevação de nível de base durante a última deglaciaçáo, registrada globalmente entre $-22-18$ ka até -8 ka A.P. (Fig. 7), resultou numa rápida transgressáo marinha na plataforma continental e no 

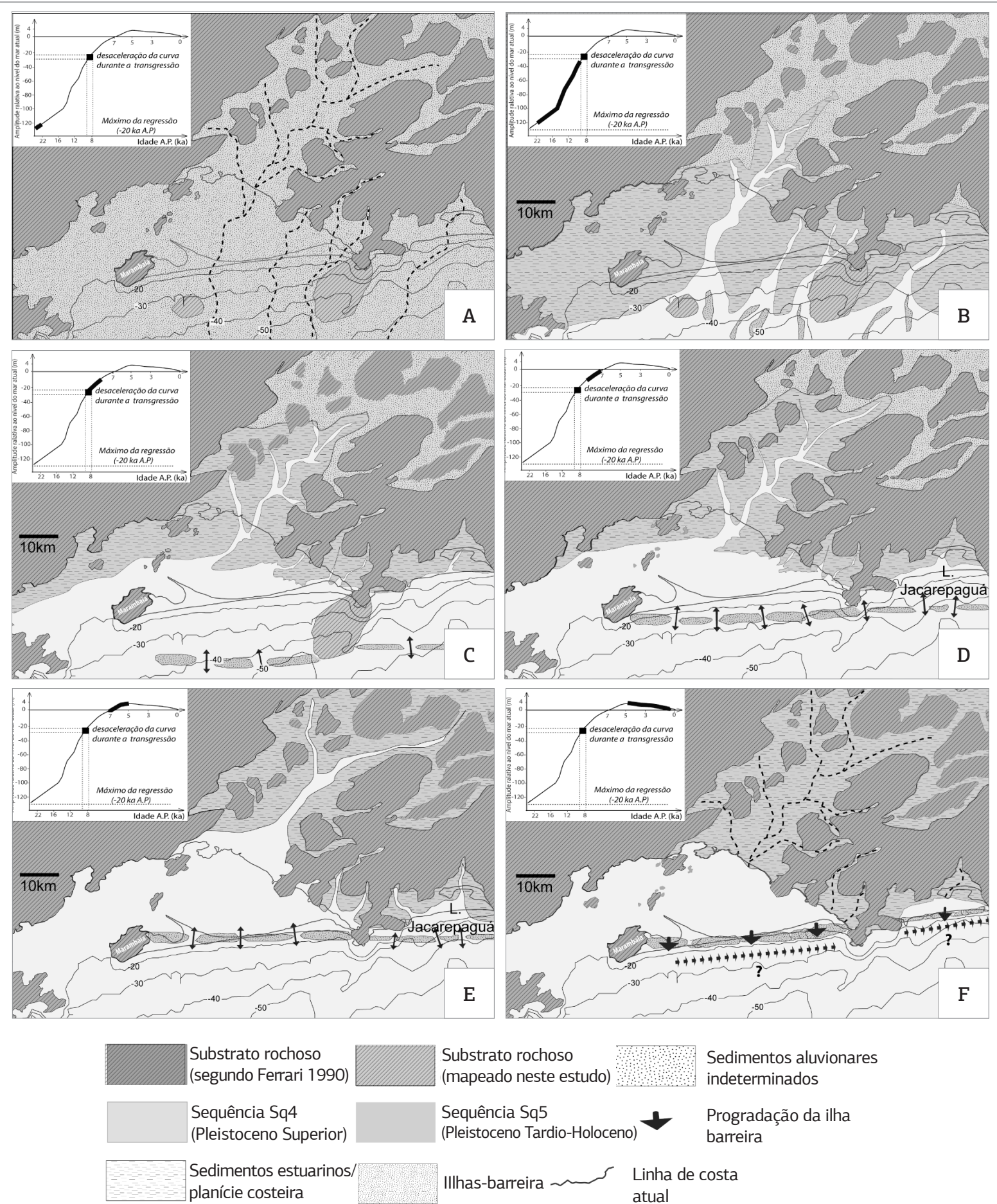

Substrato rochoso
(mapeado neste estudo)

Sequência Sq5

(Pleistoceno Tardio-Holoceno) Illhas-barreira S L L L L $\begin{aligned} & \text { Linha de costa } \\ & \text { atual }\end{aligned}$

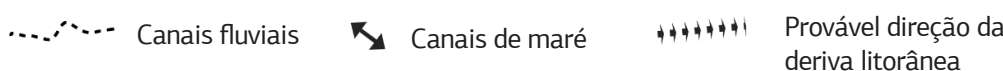

Figura 9. Modelo paleogeográfico simplificado da formação do sistema estuarino de Sepetiba e sua evolução de um sistema aberto a semifechado, desenvolvido durante a última deglaciação (últimos 22 - $18 \mathrm{ka}$ ). Este modelo simplificado baseia-se na análise sísmica e no empilhamento estratigráfico de fácies acústicas observadas em linhas sísmicas de alta resolução (fonte Boomer de 200 - $300 \mathrm{~J}$ de potência), adquiridas na plataforma rasa até cerca de 50 - 60 m de lâmina d'água à frente da Restinga da Marambaia. A curva simplificada de variação do nível do mar para os últimos 22 ka é composta pelas posições de nível do mar abaixo do atual inferidas por medições de isótopos estáveis em corais na região de Barbados (Bard et al. 1990) e pela posição de nível do mar proposta por Angulo et al. (2006) para o litoral sudeste brasileiro para os últimos $\sim 7$ ka. Os dados estratigráficos referentes à área à frente da Lagoa de Jacarepaguá são oriundos de Toulemonde (2012). 
rápido afogamento do sistema fluvial. Esse período registra a implantação de um sistema estuarino aberto, em porções mais distais que a da atual Restinga da Marambaia (Fig. 9B). A implantação desses ambientes estuarinos é atestada pelo registro estratigráfico da base da sequência Sq5 (unidade sísmica $\mathrm{U}_{4}$ ), de densa e complexa rede de feições canalizadas com evidências de múltiplas e sucessivas migraçóes laterais de um sistema fluvio-estuarino (Fig. 6);

- Uma importante modificação na configuraçáo geográfica, e na dinâmica do sistema estuarino, se evidencia pela presença de várias geraçôes de canais rasos (de até $-5 \mathrm{~m}$ de profundidade) preservados na base das unidades sísmicas $U_{6}$ e $U_{7}$, com feições de intensa migração lateral (Figs. 4, 5 e 8). Esses canais foram interpretados como canais de maré, testemunhos da construção de ilhas-barreira descontínuas na boca dos paleoestuários, e logo do início da configuração de estuários parcialmente fechados. $\mathrm{O}$ desenvolvimento dessas feiçóes transgressivas foi provavelmente favorecido pela desaceleração da transgressão a partir de $-8 \mathrm{ka}$, como indicada em curvas globais de variaçóes eustáticas (por exemplo Bard et al. 1990; Fig. 7). A presença dos canais de maré em porçóes cada vez mais proximais e estratigraficamente mais elevadas, seguidas de sua inativação, da destruição das ilhas-barreira e de seu recobrimento por unidades deposicionais marinhas, evidencia que as ilhas-barreira são feiçóes transgressivas de caráter bastante efêmero que não tendem a ser preservadas no registro sismoestratigráfico, mesmo durante a desaceleração de elevação eustática entre $-8-5 \mathrm{ka}$, ou seja, até o máximo transgressivo registrado na área (Figs. 9C e E). A presença de porçóes do embasamento aflorante à época (Fig. 9C) pode ter servido de ancoragem física para a deposição temporária das ilhas-barreira, à exemplo das atuais ilhas-barreira que isolam parcialmente a Baía de Sepetiba e a Lagoa de Jacarepaguá (Figs. 9D e E);

- O registro sismoestratigráfico da área evidencia que a atual Restinga da Marambaia corresponde arquiteturalmente à deposição de uma feição regressiva, estratigraficamente correlata ao topo da sequência Sq5 (topo da unidade sísmica $U_{7}$; Figs. 6 e 8). Nesse sentindo, a atual configuração da Baía de Sepetiba, isolada por uma ilha-barreira contínua de cerca de $45 \mathrm{~km}$ de comprimento (Fig. 1), representaria uma nova modificação ambiental e dinâmica do estuário. Juntamente ao caráter regressivo de deposição da restinga atual, a ausência de canais de maré no registro sismoestratigráfico recente indica modificação na dinâmica deposicional; a progradação da feiçáo linear e contínua indica provavelmente a atuação da deriva litorânea como componente dinâmico coadjuvante na sua deposição (Fig. 9F).

Desse modo, a análise sismoestratigráfica conduzida neste trabalho indica que o fechamento parcial do sistema estuarino de Sepetiba evoluiu através de uma sucessão de fases de construção e destruição de ilhas-barreira isoladas, cujo único registro atual são os paleocanais de maré preservados. A restinga atual é correlata a uma fase deposicional regressiva, iniciada após o máximo transgressivo na região, apontado por vários autores como tendo ocorrido há $-5,8$ ka A.P. (Martin et al. 2003, Angulo et al. 2006; Fig. 7).

\section{AGRADECIMENTOS}

Os autores agradecem à CAPES (Edital Ciências do Mar, processo 23038.051609/2009-61), CNPq (Edital Universal, processos 474004/2010-4 e 476183/2010-3) e FAPERJ (processos E-26/110.812/2008, E-26/110.161/2009, E-26/101.519/2009 e E-26/102.254/2009), pelo apoio financeiro concedido para a realização deste trabalho. Agradecemos também à CAPES pela bolsa de mestrado concedida ao primeiro autor, assim como ao $\mathrm{CNPq}$ pela concessão de bolsas de pesquisa aos segundo e terceiro autores. Agradecemos também à colaboração de três revisores anônimos, cujos comentários e sugestóes muito contribuíram para a melhoria geral do manuscrito. Esta é uma contribuição do Grupo de Pesquisa GEOMARGEM - Geologia e Oceanografia de Margens Continentais Passivas (http:// www.geomargem.org).

\section{REFERÊNCIAS}

Angulo R.J., Lessa G.C., Souza M.C. 2006. A critical review of midto late-Holocene sea-level fluctuations on the eastern Brazilian coastline. Quaternary Science Reviews, 25(5-6):486-506.

Bard E., Hamelin B., Fairbanks R.G. 1990. U-Th ages obtained by mass spectrometry in corals from Barbados: sea level during the past 130,000 years. Nature, 346:456-458.
Catuneanu O. 2006. Principles of Sequence Stratigraphy. Oxford, Elsevier, 375 p.

Carvalho Silva A.L. 2011. Arquitetura sedimentar e evolução geológica da planície costeira central de Maricá (RJ) ao longo do Quaternário. Tese de doutorado, Programa de Pós-graduação em Geologia e Geofísica Marinha, Universidade Federal Fluminence, 185 p. 
Dalrymple R.W., Zaitlin B.A., Boyd R. 1992. Estuarine Facies Models: Conceptual basic and stratigraphyc implications. Journal of Sedimentary Petrology, 62(6):1130-1146.

Chaumillon E., Tessier B., Reynaud J-Y. 2010. Thematic issue: French incised valleys and estuaries. Bulletin de la Société Géologique de France, 181(2):75-224.

Ferrari A.L. 1990. A geologia do "rift" da Guanabara (RJ) na sua porção centro ocidental e sua relação com o embasamento précambriano. In: Congresso Brasileiro de Geologia, 36, Natal, Anais. Natal: SBG, 6:2851-2872

Hunt D. \& Tucker M.E. 1992. Stranded parasequences and the forced regressive wedge systems tract: deposition during base-level fall. Sedimentary Geology, 81:1-9.

Klein D.A. 2005. Registros de variações ambientais no Canal de São Sebastião (Estado de São Paulo), durante o Último Ciclo Glacial. Tese de Doutorado, Universidade de São Paulo, São Paulo, 85 p.

Mahiques M.M., Souza S.H.M., Furtado V.V., Tessler M.G., Toledo F.A.L., Burone L., Figueira R.C.L., Klein D.A., Martins C.C., Alves D.P.V. 2010. The southern Brazilian shelf: general characteristics Quaternary evolution and sediment distribution. Brazilian Journal of Oceanography, 58(2):25-34.

Maia R.M.C., Reis A.T., Alves E.C., Silva C.G., Guerra J.V., Gorini C., Silva A., Arantes-Oliveira R. 2010. Architecture and stratigraphic framework of shelf sedimentary systems off Rio de Janeiro state, northern Santos basin-Brazil. Brazilian Journal of Oceanography, 58(2):15-29.

Martin L., Dominguez J.M.L., Bittencourt A.C.S.P. 2003. Fluctuating Holocene sea levels in eastern and southeastern Brazil: Evidence from multiple fossil and geometric indicators. Journal of Coastal Research, 19(1):101-124.

Mitchum Jr. R.M. \& Vail P.R. 1977. Seismic stratigraphy and global changes of sea-level. Part 7: stratigraphic interpretation of seismic reflection patterns in depositional sequences. In: Payton, C.E. (ed.) Seismic Stratigraphy - Applications to Hydrocarbon Exploration. Oklahoma, American Association of Petroleum Geologists Memoir, 26:135-144.

Plint A.G. \& Nummedal D. 2000. The falling stage systems tract: recognition and importance in sequence stratigraphy. In: Hunt, D., Gawthorpe, R. (eds) Sedimentary responses to forced regressions. London, Geological Society, Special Publications, 172:1-17.

Rabineau M., Berné S., Aslanian D., Olivet J.L., Joseph P., Guillocheau F., Bourillet JF., Ledrezen E., Granjeon D. 2006. Paleo sea levels reconsidered from direct observation of paleoshoreline position during Glacial Maxima (for the last 500,000 yr). Earth and Planetary Science Letters, 252:119-137.

Reis A.T.,MaiaR.M.,SilvaC.G.,RabineauM.,GuerraJ.V.,GoriniC.,AyresA., Arantes-Oliveira R., Benabdellouahed M., Simões I.V., Tardin R. (no prelo). Origin of step-like and lobate seafloor features along the continental shelf off Rio de Janeiro State, Santos basin-Brazil. Geomorphology, Drowned Landscape special volume, 30 p.

Silva A. 1992. Evolução sedimentar pós-miocênica na área nordeste da Bacia de Campos. Dissertação de Mestrado, Instituto de Geociências, Universidade Federal do Rio de Janeiro, Rio de Janeiro, 57 p.

Toulemonde B. 2012. Evolution sédimentaire des environnements côtiers du littoral de l'Etat de Rio de Janeiro (Brésil) au cours de l'Holocène. Memoire de stage. Master 2 Recherche Ingénierie et Géosciences du Littoral, Université de Caen Basse-Normandie, France, Océanographie, UERJ, Brésil, 51 p.

Zalán P.V. \& Oliveira J.A.B. 2005. Origin and structural evolution of the Cenozoic Rift System of Southeastern Brasil. B. Geoci. Petrobras, Rio de Janeiro, 13(2):269-300.

Arquivo digital disponível on-line no site www.sbgeo.org.br 